\title{
The Effectiveness of the Integrated Health Promotion Program for the Elderly
}

\author{
Ui Chan Hwang ${ }^{1}$, Han Ra Cho ${ }^{2}$, Yeong Hun $\mathrm{Yeo}^{3}$ \\ ${ }^{1}$ Doctoral Student, 54896 Dept. Social Welfare, Jeonbuk Natl.Univ., Korea, 979chani@ hanmail.net \\ ${ }^{2}$ Researcher, 16429 Suwon Research Institute, Korea, halla_c@daum.net \\ ${ }^{3}$ Associate Professor, 54896 Dept. Social Welfare, Jeonbuk Natl.Univ., Korea, yhyeo2@gmail.com \\ Corresponding author: Yeong Hun Yeo
}

\begin{abstract}
As the elderly population has been rapidly increasing, interest in health in senescence has been amplified, and diverse health programs for the elderly have been implemented. The integrated health promotion program for the elderly attempted to overcome the limitations of the existing fragmented and scattered health programs for the elderly. First, a health promotion program incorporating the three topics of dementia, depression, and fall risk was planned, and a one-on-one customized program was implemented by visiting elderly households for multilateral aspects of physical and mental health. Second, a standardized manual was prepared, and the generalization of the manual is being attempted with 2,900 elderly persons who use 34 welfare facilities for the elderly in Jeollabuk-do. The purpose of this study is to examine the effectiveness of the visiting type integrated health promotion program. Changes in dementia, suicidal ideation, cognitive ability, fall risk, and ambulatory function ability were examined using the pre-and post-paired t-tests with 278 elderly persons in six institutions. Based on the results, positive effects of the program appeared in all areas except for the risk of falls. The results of single regression analyses, in which the amounts of changes in five health elements were used as dependent variables, showed that gender and age were not significant, indicating that the effects of the program were universal regardless of gender or age. The study results supported the effectiveness and important role of the integrated health promotion program for the elderly by verifying health improvement among the program participants.
\end{abstract}

Keywords: Integrated Health Promotion Program, Elderly, Depression, Dementia, Fall Risk, Program Evaluation

\section{Introduction}

The ratio of the elderly population in South Korea reached $7 \%$ of the entire population corresponding to an aging society in 2000 and $14.2 \%$ corresponding to an aged society in 2018 , and is expected to reach $20.25 \%$ corresponding to a super-aged society in 2025 and about $34 \%$ in 2040[1].

Along with the rapid increase in the elderly population in South Korea, the prevalence of dementia has been also increasing. According to a data from the Ministry of Health and Welfare in 2020, the prevalence rate of dementia among the elderly aged at least 65 years in South Korea in 2018 was $10.16 \%$, which corresponds to about 750,000 persons. On reviewing the progress of the number of dementia patients, it is estimated that the number of dementia patients will reach one million in 2024, two million in 2039 , and three million, which corresponds to a dementia prevalence rate of $16.09 \%$, in 2050 . The

Received: September 14, 2020; 1st Review Result: November 03, 2020; 2nd Review Result: December 23, 2020 Accepted: January 25, 2021 
national dementia management cost in 2018 was 15.03 trillion won, which accounted for about $0.8 \%$ of the GDP, and the cost burden is expected to continuously grow due to increases in dementia prevalence [2].

Meanwhile, according to the '2018 Suicide Statistical Data Book'[3] published by the Korea Suicide Prevention Center, the number of suicides per 100,000 people in South Korea was 24.6 (as of 2016), which was much higher compared to the OECD average of 11.5, and that among the elderly aged at least 65 years was 53.3, which was extremely higher compared to the OECD average of 18.4. As for the suicide motives by age group, those under the age of 30 were surveyed as mental problems, those aged 31 to 60 years old were surveyed as problems of economic life, and those aged 61 and older were surveyed as having physical illness. These results mean that older people feel the most painfully unhealthy lives. In previous studies, it has been reported that the elderly with depression had suicidal ideation five times more frequently than the elderly without depression[4], that the effect of depression on the quality of life of the elderly was very large, and that the depression of the elderly was a primary factor that had the largest effect on healthy aging[5][6]. Therefore, for healthy aging, a practical approach to preventing depression and minimizing physical illness is needed.

As the elderly population increases, the safety accident rate among the elderly is also increasing. According to the '2019 Consumer Hazard Information Trend and Statistical Analysis' of the Korea Consumer Agency, the number of safety accidents of the elderly aged 60 or older that were reported to the Korea Consumer Risk Monitoring System was 7,183 in 2016, 7,249 in 2017, 8,005 in 2018, 8,356 in 2019[7]. Among the safety accidents of the elderly, physical shocks occurred the most, and among the physical shocks, "sliding and falling" was the most common with 13,110 cases (18.0\%). As for the detailed hazardous areas due to 'sliding and falling', 'head and face (24,359 cases / 33.4\%)' was the most common. In addition, $10.1 \%$ of the elderly 65 years or older who received health check-ups in 2018 were surveyed as being at high risk group of falls[8].

As stated above, dementia, depression, and falls are factors that affect the lives of the elderly, and preventive approaches are needed to extend the period of healthy old age by preventing or delaying them, rather than approaches based on the belief that they are natural phenomena occurring in the general aging process[9].

Diverse programs such as cognitive function training workbooks, singing classes, gymnastics for all, outings, and teaching tool play have been developed and applied in the field of welfare for the aged. However, depending on the organizations or institutions that provide the programs, differences in the level of use of the programs by individuals may occur or those elderly persons who cannot participate in facilities or organizations that operate group programs using facilities (e.g. centers for senior citizens, community welfare centers, religious organizations, nursing homes, nursing hospitals, day and night protection centers, etc.) cannot but be excluded from the programs. In particular, the reality is that it is not easy for programs operated as group programs to be provided systematically and continuously in consideration of individuals' health conditions and preferences of programs.

On the other hand, community care services for the elderly that firsthand visit elderly households to provide services in order to support the independent life of the underprivileged and unhealthy elderly are operated focusing on services for promotion of convenience centered on housework services, external activity support service, emotional support service, and regional resource linkage despite that they are delivery systems suitable for providing systematic health promotion programs through individual approaches. Therefore, to prevent unequal use of the programs or the occurrence of blind spots, it would be desirable to apply a health promotion program that integrated dementia prevention, depression prevention, and fall prevention activities to community care services for the elderly project $\mathrm{s}[10]$.

Therefore, in this study, a health promotion program that integrated programs to prevent dementia, depression, and falls, which are major factors that affect the quality of life of the elderly, was developed. 
It was applied to community care services for the elderly where the effectiveness of the program was evaluated. This could help the increasing elderly generations enhance their satisfaction with their personal lives through healthy aging and plays a role as a resource to reduce the burden of society[11].

The research questions in this study are as follows.

First, have the integrated health promotion program improved the mental health and physical health of the participants?

Second, what sociodemographic backgrounds is linked to the health improvement of the pram participants?

\section{Theoretical Background}

\subsection{Dementia}

Dementia refers to a multiple disorder that interferes with daily life by declining functions such as memory, language ability, orientation, judgment, and performance due to degenerative brain disease or cerebrovascular disease (Article 2 of the Dementia Control Act). Dementia can be said to be a tragic disease that destroys the patient's own personality and devastates even the lives of those who support them[12].

According to the Ministry of Health and Welfare's Korea Dementia Status 2019 Report, of the 750,488 dementia patients 65 years of age or older in 2018, Alzheimer's type was 559,214, or 75.5\%, and vascular dementia was 66,132 , or $8.8 \%$, and both types accounted for $84.3 \%$ of all dementia types[2].

\subsection{Depression}

Depression is an emotional anxiety state that accompanies emotional and physical behaviors such as persistent sadness, despair, emptiness, headache, loss of appetite, lack of sleep, and nervous behavior[13]. They think and feel that they are alone, cannot give or receive love, and therefore not worthy of being loved, and in the extreme, even have the urge to commit suicide[14].

According to the "Ministry of Health and Welfare 2017 Survey on the Elderly," the higher the age, the higher the rate of depressive symptoms. The 65-69-year-old group was 15.1\%, the 75-79-year-old group was $23.6 \%$, and the 85 -year-old group was $33.1 \%$, and the 85 -year-old group had more than twice the rate of depression in the 65-69-year-old group[15].

\subsection{Fall}

In Korea, 'Fall' generally mean injuries due to slipping or falling, and WHO refers to 'fall' as "the main external cause of unintended injuries, generally unintentionally falling to the ground, floor or low position"[16].

With the increase of the elderly population, the "safety accident rate of the elderly" is also increasing. According to the Consumer Protection Agency's 2019 consumer risk information trend and statistical analysis, the number of safety accidents of the elderly over 60 years old received by the Korea Consumer Risk Monitoring System was 7,183 cases in 2016 and 7,249 cases in 2017, 8,005 cases in 2018, and 8,356 cases in 2019 , showing a continuous increase. In addition, physical shock was the highest among all accidents, and "sliding, falling" was the cause of the most physical shock with 13,110 cases $(18.0 \%)[7]$.

The most detailed hazardous area caused by "slipping and falling" is "head and face" with 24,359 cases (33.4\%). Of all safety accidents, physical shocks for those aged 60 and over accounted for $62.1 \%$ (5,189 cases), more than half of those for the same age group, and 2,354 cases $(28.2 \%)$ of injuries to the 
"head and face" of the physical shocks. This is the highest number in the same age group[7]. In addition, $10.1 \%$ of the elderly 65 years of age or older who received health check-ups in 2018 were in the fall high risk group. This means that the risk of falls among the elderly is very high[8].

Of the total fall accidents, $25.9 \%$ were domestic accidents, $41.7 \%$ of the elderly over 65 years old, and the fall accident rate was $11.9 \%$ when there was a walking ability problem, about three times higher than $3.7 \%$ when there was no problem with walking ability. Also, the fall accident rate of the elderly with depression was $7.4 \%$, which was twice as high as that of the elderly without depression[17].

\section{Integrated Health Promotion Program for the Elderly}

The integrated health promotion program for the elderly is a relationship-based program in which the same provider gives function promotion programs for the prevention of dementia, depression, and falls that directly affect elderly persons' ability. It aims to conduct activities of daily living and quality of life and was developed to contribute to the realization of elderly persons' sustainable living in the community by promoting participants' motivation for participation and comprehensively observing individuals' functional statuses there by providing personalized services.

The integrated health promotion program for the elderly, developed in 2017, was implemented as a pilot project for two years until 2018 and distributed to organizations implementing community care service projects in the Jeonbuk region from 2019. The program was operated as a group-type program and a visiting-type program at the stage of the pilot project, but currently, it is mainly operated as a visiting-type program with high accessibility. As of August 2020, about 2,900 elderly persons among the users aged at least 65 years of 34 welfare facilities for the elderly (29 community care facilities for the elderly, 4 senior welfare centers and 1 social welfare center) were participating in the program. The program was implemented in a one-on-one customized type by care workers who visit elderly households once a week, for 30 minutes, and the program was managed by the social workers at individual facilities. The program was implemented using the workbook published every month, and the workbook divides the program into parts for four weeks to present learning contents for the prevention of dementia, depression, and falls every week. In addition, the workbook contained contents regarding diet management, oral management, and life information once a month, and enabled program implementing organizations to grasp the degree of participation in the program every week through observation record sheets.

Among the contents of the program, the 'Dementia Prevention' is composed of contents to improve cognitive functions centering on orientation, calculation ability, problem solving ability, memory, and visual perceptual ability. The 'Depression Prevention' is composed of contents that can promote positive emotional stability through communion with the program provider such as nail art, coloring, puzzle making, recalling technique, and play, and includes physical activities such as paper cutting-and-pasting, origami, and play using teaching tools to promote and sustain educational participants' interest. The 'Fall Prevention' centers on stretching and lower body strengthening exercises considering the lower body muscle weakening following aging.

The difference of the fall prevention program as a program conducted through a workbook is that it is a couple activity in which the program host and the user hold hands with each other. The purposes of developing the fall prevention activity as a couple activity are to promote the participation of program users, to prevent safety accidents of program users, and to maintain the health of the program host. This differentiation of the program creates a program atmosphere so that users can perceive the program as a fun play time rather than boring learning, thereby minimizing the rejection of the user's participation in the program. In addition, most of the exercises to strengthen the hip and thigh muscles include movements to strengthen the sense of balance, and safety accidents that may occur can be prevented by couple activities. In particular, most middle-aged program hosts participate in fall prevention activities 
together with users to maintain or improve their own health, and through this, more stable and active progress of the program can be expected.

An important consideration when operating this program is that the program must be completed within 20 minutes. This program should be completed within an hour on average, including the existing welfare service for the elderly in home, in situations where the service needs of program users are diverse and complex. This is because if the program exceeds the appropriate time, it is highly likely that it will interfere with the performance of other home-based elderly welfare services, and complaints may arise to both users and hosts. Therefore, for stable program operation, it is necessary to continuously provide education on program progress for program managers.

An advantage of the integrated health promotion program for the elderly is that, unlike the existing health promotion programs for the elderly which are operated as group programs centering on the facilities used, the program coordinators visit homes to implement 1:1 individually tailored programs according to the users' individual health conditions and preferences thereby continuously providing motivation to participate in the program and enhancing the effectiveness of health promotion.

In addition, since the existing health promotion programs for the elderly are selectively provided according to the circumstances and interests of individual facilities, differences in quantitative and qualitative levels may occur among program users, but such differences can be resolved by providing standardized programs.

Existing health promotion programs for the elderly fragmentally applied the area of mental health (prevention of dementia) or the area of physical health depending on the characteristics of the facilities that operate the program or the organizations that provide the program in many cases. However, this program has a great advantage as a program suitable for supporting the independent life of the elderly by comprehensively approaching the mental health area comprising dementia and depression and the physical health area called fall prevention.

\section{Research Method}

\subsection{Research Subjects and Data Collection}

The subjects of this study are the participants of the integrated health promotion program for the elderly among community elderly support service users in Jeollabuk-do. The data of 278 participants who participated in both the pre-test and post-test among the program participants of six institutions were used for the final analysis. The pre-test was conducted on March 2018 and the post-test was conducted on December 2018.

In consideration of the ethical aspect of the study, the purpose of the study and the protection of personal information were explained. Also, the study was conducted with the consent of the study participants. In addition, even if they agreed to participate in the study, if a study participant wishes to stop, they could quit at any time.

\subsection{Research Instrument}

The measurement tools used in this study are shown in [Table 1]. Depression was measured with depressive states during the last week using the Korean version of the short form of Geriatric Depression Scale (SGDS-K) as a measuring tool. The SGDS-K[6] was measured using a 4 point scale consisting of 'Extremely rare (one day or less)' 1 point, 'Occasionally(1 2 days)' 2 points, 'Once in a while (3 4 days)' 3 points, and 'Mostly so (5 7 days)' 4 points. Higher scores mean higher levels of depression. In this study, Cronbach's alpha coefficient was .741, and the reliability was secured.

Suicidal ideation was measured with the feelings and behaviors within the last six months using the 
Suicide Ideation Scale (SIS) as a measuring tool. The SIS was measured using a 4-point scale ranging from 'not at all so (1 point)' to 'very much so (4points)'. Higher scores mean higher levels of suicidal ideation. In this study, Cronbach's alpha coefficient was .845, and the reliability was secured.

Cognitive functions were measured by grasping overall cognitive functions using the Mini-Mental Status Examination-Korea (MMSE-K)[16]. The MMSE-K measured 'orientation, memory registration of three words, concentration, calculation, word recall, language and spatial composition' using a total of 12 items (perfect score; 30 points). Higher scores mean better cognitive functions.

Ambulatory function was measured using the ambulatory function scale (Timed up and go test: TUG)[8]. Shorter time taken to walk three meters means better ambulatory function.

Fall risk was measured using Huhn's fall risk assessment tool consisting of a total of 7 items such as experience of falling, mental state, and sense of balance. The scores range up to 28 points, and higher total scores mean higher levels of fall risk.

[Table 1] Summary of Measurement Tools

\begin{tabular}{|c|c|c|c|c|}
\hline Variables & Scale & Number of Questions & Range & Cronbach's a \\
\hline Depression & SGDS-K & 10 & $10 \sim 40$ & .741 \\
\hline Suicidal Ideation & $\begin{array}{l}\text { Suicide Ideation Scale } \\
\text { (SIS) }\end{array}$ & 5 & $5 \sim 20$ & .845 \\
\hline Cognitive Functions & MMSE-K & 12 & $0 \sim 30$ & N/A \\
\hline Ambulatory Function & $\begin{array}{l}\text { Timed up and go test } \\
\text { (TUG) }\end{array}$ & 1 & - & N/A \\
\hline Fall Risk & Huhn's fall risk & 7 & $1 \sim 20$ & N/A \\
\hline
\end{tabular}

\subsection{Analysis Method}

The data collected in this study were analyzed as follows using the SPSS 24.0 program. First, frequency analysis was conducted to find out the sociodemographic characteristics of the survey subjects. Second, the differences between the resultant values in the pre-test and the post-test were analyzed for depression, suicidal ideation, cognitive function, ambulatory function, and fall risk to identify the effectiveness of the visiting type integrated health promotion program. Finally, simple linear regression analyses were conducted for the amounts of changes (amount of change $=$ pre-test measured value-post-test measured value) in individual variables to identify whether the sociodemographic characteristics of the survey subjects affect the effectiveness of the visiting type integrated health promotion program.

\section{Research Results}

\subsection{Sociodemographic Characteristics of Survey Subjects}

The sociodemographic characteristics of the survey subjects are as shown in [Table 2]. Among the entire survey subjects, $53(19.1 \%)$ were males and $224(50.6 \%)$ were females. Therefore, females outnumbered males. Age groups were shown to be $128(46.0 \%)$ in their $80 \mathrm{~s}, 122(43.9 \%)$ in their $70 \mathrm{~s}$, $12(4.3 \%)$ in their $90 \mathrm{~s}$ or older, and $14(5.0 \%)$ in their $60 \mathrm{~s}$, and the average age was identified as 79.49 years. 
[Table 2] Demographic and Sociological Characteristics of Survey Subjects ( $N=278)$

\begin{tabular}{|c|c|c|c|}
\hline \multicolumn{2}{|r|}{ Variables } & $\mathrm{N}$ & $\%$ \\
\hline \multirow{3}{*}{ Sex } & Male & 53 & 19.1 \\
\hline & Female & 334 & 80.6 \\
\hline & Missing & 1 & .4 \\
\hline \multirow{5}{*}{ Age Groups } & $60 \mathrm{~s}$ & 14 & 5.0 \\
\hline & $70 \mathrm{~s}$ & 122 & 43.9 \\
\hline & $80 \mathrm{~s}$ & 128 & 46.0 \\
\hline & 90 s or older & 12 & 4.3 \\
\hline & Missing & 12 & .7 \\
\hline \multirow{5}{*}{$\begin{array}{l}\text { Educational } \\
\text { Backgrounds }\end{array}$} & Uneducated & 163 & 58.6 \\
\hline & Elementary school graduate & 66 & 23.7 \\
\hline & Middle school graduate & 17 & 6.1 \\
\hline & High school graduate or higher & 28 & 10.1 \\
\hline & missing & 4 & 1.4 \\
\hline \multirow{2}{*}{ Marital Statuses } & Have the spouse & 86 & 30.9 \\
\hline & Bereavement, divorce, no marriage, etc. & 192 & 69.1 \\
\hline \multirow{4}{*}{ Earnings Category } & Recipients & 200 & 71.9 \\
\hline & Low earners & 65 & 23.4 \\
\hline & General earners & 9 & 3.2 \\
\hline & missing & 4 & 1.4 \\
\hline \multirow{6}{*}{$\begin{array}{c}\text { Subjective Health } \\
\text { Status }\end{array}$} & Very bad & 15 & 5.4 \\
\hline & bad & 99 & 35.6 \\
\hline & Medium & 148 & 53.2 \\
\hline & Good & 13 & 4.7 \\
\hline & Very good & 1 & .4 \\
\hline & \multirow[t]{2}{*}{ missing } & 2 & .7 \\
\hline \multirow{2}{*}{\multicolumn{2}{|c|}{ Age }} & $\mathrm{M}$ & S.D. \\
\hline & & 79.49 & 6.00 \\
\hline \multicolumn{2}{|c|}{ Average Monthly Income } & 39.36 & 11.36 \\
\hline
\end{tabular}

As for the educational backgrounds, the number of those who were uneducated was the largest at 163 (58.6\%), and $66(23.7 \%)$ were shown to be elementary school graduates. As for marital statuses, 86 (30.9\%) had a spouse, and $192(69.1 \%)$ had no spouse due to bereavement, divorce, or no marriage. As for the protection categories, $200(71.9 \%)$ were shown to be basic livelihood security recipients and 65 (23.4\%) were shown to be low earners. Therefore, most of the subjects were shown to be basic livelihood security recipients or low earners and the average monthly income was shown to be about 394,000 won. As for subjective health conditions, $148(53.2 \%)$ were found to be moderate and $99(35.6 \%)$ were found to be bad.

\subsection{Verification of Differences between Before and After the Program}

To check the effectiveness of the visiting type integrated health promotion program, the differences between the results of measurement of depression, suicidal ideation, cognitive ability, ambulatory function, and fall risk before and after the program were verified and the results are shown in [Table 3].

First, the average depression score before the program was 1.49 points $(\mathrm{SD}=.48)$, and that after the program was 1.44 points $(\mathrm{SD}=.41)$. Therefore, the average depression score decreased by .05 point after the program and this difference was statistically significant $(\mathrm{t}=2.021, \mathrm{p}<.05)$. The average suicidal ideation score before the program was 1.15 points $(\mathrm{SD}=.33)$ and that after the program was 1.08 points 
$(\mathrm{SD}=.22)$. Therefore, the average suicidal ideation score decreased by .07 point after the program and this difference was statistically significant $(\mathrm{t}=.3 .653, \mathrm{p}<.01)$. The average cognitive ability score before the program was 23.62 points $(\mathrm{SD}=4.74)$, and that after the program was 24.49 points $(\mathrm{SD}=4.27)$. Therefore, the average cognitive ability increased by .87 points and this difference was statistically significant $(\mathrm{t}=-3.949, \mathrm{p}<.01)$.

[Table 3] Depression, Suicidal Thoughts, Cognitive Ability, Gait Function, Fall Risk Pre-and PostVerification

\begin{tabular}{|c|c|c|c|c|}
\hline \multicolumn{2}{|c|}{ Variables } & M & S.D. & $\mathrm{t}$ \\
\hline \multirow{2}{*}{$\begin{array}{l}\text { Depression } \\
(\mathrm{N}=271)\end{array}$} & pre & 1.49 & .48 & \multirow{2}{*}{$2.021 *$} \\
\hline & post & 1.44 & .41 & \\
\hline \multirow{2}{*}{$\begin{array}{l}\text { Suicidal Ideation } \\
\qquad(\mathrm{N}=272)\end{array}$} & pre & 1.15 & .33 & \multirow{2}{*}{$3.653 * * *$} \\
\hline & post & 1.08 & .22 & \\
\hline \multirow{2}{*}{$\begin{array}{l}\text { Cognitive Functions } \\
\qquad(\mathrm{N}=277)\end{array}$} & pre & 23.62 & 4.74 & \multirow{2}{*}{$-3.949 * * *$} \\
\hline & post & 24.49 & 4.27 & \\
\hline \multirow{2}{*}{$\begin{array}{l}\text { Ambulatory Function } \\
\qquad(\mathrm{N}=266)\end{array}$} & pre & 22.08 & 18.80 & \multirow{2}{*}{$8.726 * * *$} \\
\hline & post & 13.05 & 5.07 & \\
\hline \multirow{2}{*}{$\begin{array}{c}\text { Fall Risk } \\
(\mathrm{N}=276)\end{array}$} & pre & 8.81 & 3.39 & \multirow{2}{*}{-.826} \\
\hline & post & 8.96 & 3.38 & \\
\hline
\end{tabular}

$* \mathrm{p}<.05, * * \mathrm{p}<.01, * * * \mathrm{p}<.001$

The ambulatory function was measured with the time taken to walk three meters. The average time was shown to be 22.08 seconds $(\mathrm{SD}=18.80)$ before the program and 13.05 seconds $(\mathrm{SD}=5.07)$ after the program. Therefore, the time was shortened by 9.03 seconds after the program and this difference was statistically significant $(\mathrm{t}=8.726, \mathrm{p}<.01)$. The average fall risk score was 8.81 points $(\mathrm{S} . \mathrm{D}=3.39)$ before the program and 8.96 points $(\mathrm{S} . \mathrm{D}=3.38)$ after the program and this difference was not statistically significant. That is, when the scores before and after the program were compared, it was found that depression and suicidal ideation decreased, and cognitive ability and ambulatory ability improved.

\subsection{Factors Influencing the Effectiveness of the Visiting Type Integrated Health Promotion Program}

Simple linear regression analyses were conducted to identify the sociodemographic characteristics of the survey subjects that affect changes in depression, suicidal ideation, cognitive ability, ambulatory function, and fall risk, and the results are as shown in [Table 4].

[Table 4] Factors Influencing the Effectiveness of the Integrated Health Promotion Program for the Elderly

\begin{tabular}{|c|c|c|c|c|c|}
\hline \multirow{2}{*}{ Variables } & Depression & Suicidal Ideation & $\begin{array}{c}\text { Cognitive } \\
\text { Functions }\end{array}$ & $\begin{array}{c}\text { Ambulatory } \\
\text { Function }\end{array}$ & Fall Risk \\
\cline { 2 - 6 } & $\mathrm{B}$ & $\mathrm{B}$ & $\mathrm{B}$ & $\mathrm{B}$ & $\mathrm{B}$ \\
\hline $\begin{array}{c}\text { Male } \\
\text { (Standard: Female) }\end{array}$ & 0.51 & .095 & -.356 & 1.097 & -.642 \\
\hline Age & -.001 & .004 & -.021 & .273 & .056 \\
\hline Education & -.001 & -.014 & .035 & $-1.614 *$ & $-.379 * *$ \\
\hline Average Monthly Income & -.002 & -.001 & $.047 *$ & $-.599 * * *$ & -.027 \\
\hline
\end{tabular}

$* \mathrm{p}<.05,{ }^{* *} \mathrm{p}<.01,{ }^{* * *} \mathrm{p}<.001$ 
First, depression and suicidal ideation did not show the effect of input sociodemographic variables. As for cognitive ability, the higher the average monthly income $(B=.047, p<.05)$, the greater the amount of change in cognitive ability. In the case of cognitive ability, it can be interpreted that the amounts of change in negative numbers have the effect to improve cognitive ability. Therefore, lower average monthly incomes had more positive effects on cognitive ability.

As for the ambulatory function, the higher the educational background $(\mathrm{B}=-1.614, \mathrm{p}<.05)$ and the monthly income $(\mathrm{B}=-.599, \mathrm{p}<.01)$, the shorter the time required to walk three meters, indicating that the ambulatory function was improved. The amount of change in fall risk was smaller when the education level $(\mathrm{B}=-.379, \mathrm{p}<.01)$ was higher. That is, the lower the education level, the larger the effect of the program to lower the fall risk.

\section{Conclusion}

The purpose of this study is to verify the effectiveness of the elderly integrated health promotion program targeting home elderly welfare service users. For this verification, 278 elderly people from six institutions who participated in the integrated health promotion program for the elderly were surveyed on depression, suicidal thoughts, cognitive ability, walking function, and risk of falling. Also, for data analysis, pre- and post-correspondence sample t-test and one-way regression analysis were conducted. The main study results are as follows.

First, the mean of depression and suicidal thoughts decreased significantly as a result of examining the changes before and after the program through the difference test. In other words, it can be said that the elderly integrated health promotion program has a positive effect on depression and suicidal thoughts. This is consistent with the results of Choi's (2002) study that the integrated service for the elderly living alone was effective in improving the emotional state of the elderly such as depression[18].

Second, as a result of examining the changes before and after the program through the difference test in cognitive ability, the average of cognitive ability increased significantly, so that the elderly integrated health promotion program can be said to be effective in improving cognitive ability. This is a different result from Choi's (2002) study showing that there was no significant change in cognitive ability before and after the program. It can be presumed that the reason for this result is that the contents of the program are different. This result appears to be because, unlike the program presented in Choi's (2002) study, which consisted of entertainment, conversation Friends Service, and food service, the integrated health promotion program for the elderly included activities to maintain and improve cognitive function (e.g., orientation activity, memory ability activity, calculation ability activity, visual perception ability activities, problem solving ability activity, etc.).

Third, as a result of examining the change after the program call through the difference verification in the gait function, the time taken to walk three meters was significantly reduced. In other words, it was verified that the elderly integrated health promotion program is effective in improving the gait function. These results are different from those of Choi's (2002), which did not show any change in gait function, and like the cognitive function results, they are interpreted as a result according to the specific contents of the program. In other words, it can be seen that the effect appeared because the activities for strengthening lower body muscles that were not included in the program presented in the study of Choi's (2002) were included in the integrated health promotion program for the elderly in this study.

Fourth, it was verified that there was no significant change in the risk of falling before and after the program. This result seems to be due to the fact that the fall risk assessment scale does not affect whether or not to use the program because the five areas (age, drug use, etc.) excluding gait, balance, and activity are composed of contents that are not likely to change.

Fifth, as a result of verifying whether the demographic and sociological background of the elderly who used the program influenced the effectiveness of the program, it was found that cognitive function, 
gait function, and fall risk were affected. Considering that most of the users of the Integrated Health Promotion Program for the Elderly are eligible and low-income elderly, it is judged that the level of functioning, which remained relatively low due to poverty, responded to the stimulation of the program. It cannot be interpreted as having an influence on the positive effects of this program.

In conclusion, the integrated health promotion program for the elderly showed positive effects to the elderly in all aspects, including depression, suicidal thoughts, cognitive ability, and gait function, excluding fall risk. In addition, it has been verified that these positive effects are generally unaffected by demographic and social characteristics.

The implications of this study are as follows.

First, group programs provided by senior citizens' welfare centers, and day care centers have been mainly introduced in the elderly welfare sites, but the integrated elderly health promotion program is significant in that it is an individual program provided to home-based elderly welfare service users.

In other words, the Integrated Health Promotion Program for the Elderly has the strength of providing a variety of activities including 1:1 home visits by employees of the provider. By proceeding the program in consideration of the physical, psychological, and emotional health of users, it can provide motivation for users to continuously participate in the program. Along with these strengths, as the effectiveness of the Integrated Health Promotion Program for the Elderly appeared, it is necessary to establish a specialized and efficient program management system so that the program can be actively used not only in Jeollabuk-do but also in other cities.

Second, through comparison with previous studies, it was verified that the area in which the effectiveness of the program appears differs according to the specific components and progress of the program. In particular, this study verified that the elderly using the program can improve cognitive and gait functions by including activities for improving cognitive function such as orientation and problemsolving ability and activities for strengthening lower body muscles. In other words, it can be said to be significant in that more in-depth research has been conducted on the integrated health promotion program for the elderly according to the specific characteristics of the program, such as the target and purpose.

The limitation of this study is the lack of a comparison group that did not participate in the program, corresponding to the group participating in the program. Therefore, in the follow-up study, it is necessary to collect data from the group participating in the program and the group who did not participate in the program and conduct a comparison study to maximize internal validity and generalization of the study results.

\section{References}

[1] Statistics Korea, 2018 Elderly Statistics, (2018)

[2] Lee Jisoo, Kang Minji, Nam Hyojung, Kim Yujung, Lee Okjin, Kim Kiwoong, Korean Dementia observatory 2019, Central Dementia Center, pp.1-385, (2019)

[3] Korea Suicide Prevention Center, 2018 Suicide Statistics Data, (2018)

[4] E. H. Lee, Predictor Variables Related to the Classification of Happy and Unhappy Elderly People: Discriminant Function Analysis, International Journal of Elderly Welfare Promotion and Management, (2018), Vol.2, No.1, pp.5762.

[5] S. S. Han, S. W. Kang, W. K. Yoo, Y. G. Phee, A Study of the Determinants of Suicidal Ideation among the Elderly in Korea, Health and Social Welfare Review, (2009), Vol.29, No.1, pp.192-212.

[6] S. I. Shin, Y. H. Kim, A Meta-Analysis on Related Variables of Elders` Quality of Life, Korean Journal of Counseling, (2013), Vol.14, No.6, pp.3673-3690, I410-ECN-0102-2014-300-001744763 
[7] Consumer Protection Agency, 2019 Consumer Hazard Information Trend and Statistical Analysis, (2020)

[8] National Health Insurance Service, Results of physical function evaluation for the elderly by health checkup statistics, (2018)

[9] Y. M. Ahn, J. Y. Ha, O. H. Yee, Demand Survey for Development of Geriatric Depression Prevention Program, International Journal of Elderly Welfare Promotion and Management, (2018), Vol.2, No.2, pp.7-12.

[10] H. J. Hyun, E. Y. Choi, M. K. Byeon, J. S. Kim, The Efficacy of Dementia Prevention Integrative Program for Cognitive function, Depression, and Quality of life in the Elderly Non-Dementia, International Journal of Elderly Welfare Promotion and Management, (2017), Vol.1. No.1, pp.43-50.

[11] Y. S. Kim, Y. H. Yeo, Study on the Trends in Life Satisfaction among the Elderly, International Journal of Elderly Welfare Promotion and Management, (2019), Vol.3, No.1, pp.7-12.

[12] H. Cho, Z. Ko, Current State of Senile Dementia and Improvement of the Long Term Care Insurance for Elderly People, Journal of the Korea Academia-Industrial Cooperation Society, (2012), Vol.13, No.12, pp.5816-5825, https://doi.org/10.5762/KAIS.2012.13.12.5816

[13] B. D. Sohn, A Study on the Comparison of Local and Incarcerated Adolescents' Characteristics and its Relationships with Depressive Symptoms and Spiritual Well-Being, Korea Youth Research Association, (2004), Vol.11, No.2, pp.371397.

[14] M. H. Kim, S. D. Chung, G. Y. Lee, Development and Evaluation of Preventive Mental Health Program for Depression among the Elderly in Community : Focused on the Community Welfare Center User, Korean Journal of Social Welfare, (2001), Vol.44, pp.318-345.

[15] Elderly Status Survey Report, Ministry of Health and Welfare, (2017)

[16] WHO Global Report on Falls Prevention in Older Age, World Health Organization, pp. 53, (2008)

[17] J. M. Kim, M. S. Lee, Risk Factors for Falls in the Elderly Population in Korea: An Analysis of the Third Korea National Health and Nutrition Examination Survey data, Korean Journal of Health Education and Promotion, (2007), Vol.24, No.4, pp.23-39.

[18] G. Choi, Evaluation of the Effectiveness of Visiting Nursing \& Home Care Cooperating Program, Journal of the Korea Gerontological Society, (2002), Vol.22, No.2, pp.147-162. 